\title{
Experiências Sociocorporais e Formação Docente em Educação Física ${ }^{1}$
}

\author{
Zenólia C. Campos Figueiredo*
}

\begin{abstract}
Resumo: O objetivo desse artigo é interpretar/compreender as experiências sociocorporais dos alunos construídas anteriormente à formação inicial em Educação Física e às experiências sociocorporais dos alunos na transição do ensino médio para o ensino superior. As experiências sociocorporais dos alunos construídas no decorrer da formação, focando a hierarquização de disciplinas, as escolhas de disciplinas e as relações com os saberes dessas disciplinas foram objeto de reflexão em um outro artigo já publicado na Revista Movimento. Busquei interpretar o fluxo das falas sociais dos alunos do curso, a partir da escrita dos "memoriais" das falas das entrevistas em grupo e individual.
\end{abstract}

Palavras-chave: Educação Física: docentes. Fatores socioeconômicos. Escolha da profissão.

\section{INTRODUÇÃo}

Em outra ocasião, antes mesmo do término da pesquisa "Experiências Sociais no Processo de Formação Docente em Educação Física" (FIGUEIREDO, 2004), publiquei um artigo na revista Movimento discutindo sobre as experiências sociocorporais construídas pelos alunos nas suas trajetórias acadêmicas, bem como a relação com o saber que os mesmos estabeleciam no decorrer de um curso de formação de professores de Educação Física. Agora, num processo inverso, que antecede à entrada desses alunos no mesmo curso investigado, busco refletir sobre as experiências

\footnotetext{
${ }^{1}$ Este artigo corresponde a uma parte revisada da tese de doutorado de minha autoria: Experiências sociais no processo de formação docente em educação física. Tese (Doutorado em Educação) - Programa de Pós-Graduação em Educação, Universidade Federal de Minas Gerais, Belo Horizonte, 2004

"Doutora em Educação pela UFMG. Docente do Centro de Educação Física e Desportos da UFES. Vitória, ES, Brasil. E-mail: zenolia@npd.ufes.br
} 
sociocorporais construídas por eles nas suas trajetórias no decorrer do ensino fundamental, no ensino médio, no momento da escolha pelo curso, indicando que essas experiências influenciaram e influenciam nas relações, interesses, e valorização de determinados conteúdos curriculares no lócus da formação.

O sentido polissêmico de experiência, podendo ser compreendida como uma maneira de sentir, individual, representada pelo "vivido" ou como atividade cognitiva, maneira de construir o real, de verificar, de experimentar, enfim, para o sociólogo, remete à experiência para o social, como uma forma de construção da realidade. "Deste ponto de vista, a experiência social não é uma 'esponja', uma maneira de incorporar o mundo por meio das emoções e das sensações, mas uma maneira de construir o mundo.”(DUBET, 1994, p. 95).

Essa noção de experiência social me fez pensar que as experiências corporais dos alunos em formação são, também, sociais, por isso venho utilizando a expressão "experiência sociocorporal".

\section{VELHOS TEMPOS! BONS TEMPOS...: AS EXPERIÊNCIAS SOCIOCORPORAIS CONSTRUÍDAS E DESCONSTRUÍDAS PELOS ALUNOS EM FORMAÇÃO NO ENSINO FUNDAMENTAL}

A forma como indiquei a elaboração do "memorial", favoreceu as lembranças dos tempos escolares vividos no ensino fundamental e médio, bem como dos registros mais ligados à Educação Física e às atividades corporais fora do espaço escolar. Busquei identificar as experiências sociais, ligadas às atividades corporais, vivenciadas pelos alunos analisando as ações que subsidiam tais

\footnotetext{
2 Pelo "memorial", primeira etapa da coleta de dados, traçou-se o perfil do aluno pesquisado por meio do registro de sua trajetória de vida que inclui a dimensão socioeconômica e aspectos relacionados com a vida escolar, abrangendo o ensino fundamental e médio. Buscou-se, também, dados sobre sua inserção no curso de Educação Física e o registro de sua experiência social relacionada ou não com a Educação Física. O termo memorial encontrase entre aspas porque foi utilizado de maneira orientada, o que pode ter sido incomum à maneira metodológica que o mesmo vem sendo utilizado nas pesquisas educacionais de abordagem qualitativa.

Movimento, Porto Alegre, v. 14, n. 01, p. 85-110, janeiro/abril de 2008.
} 
construções e as interpretações dessas experiências. Buscamos, de forma similar à etnografia, interpretar o fluxo das falas sociais dos alunos do curso, de maneira que pudéssemos entendê-las em um contexto pesquisável. Para Clifford Geertz (1987, p. 37):

$$
\begin{aligned}
& {[\ldots] \text { nossa dupla tarefa é descobrir as estruturas }} \\
& \text { conceptuais que informam os atos dos nossos su- } \\
& \text { jeitos, [...] e construir um sistema de análise em } \\
& \text { cujos termos o que é genérico a essas estruturas, o } \\
& \text { que pertence a elas, porque são o que são [...]. }
\end{aligned}
$$

Durante a interpretação preliminar realizada no decorrer do trabalho de campo e na interpretação final, foram se configurando categorias de análise que se transformaram em possibilidades de temas para um estudo mais aprofundado. Esses temas foram organizados e analisados a partir da escrita dos "memoriais" das falas das entrevistas em grupo e individual.

O "memorial" foi material propício para iniciar essa análise. Nele, encontra-se um conjunto de histórias, crenças e mitos repletos de significados, valores e atitudes que conduzem a trajetórias diferenciadas. A oportunidade de resgatar o passado, proporcionada por instrumentos do tipo do "memorial", significou, para os vinte e oito alunos do total de 121 alunos, somando: 49 cursando o $9^{\circ}$ período, 32 cursando o $5^{\circ}$ período e 40 cursando o $1^{\circ}$ período, uma proposta diferente. Nas duas fases seguintes do trabalho de campo, utilizamos a entrevista coletiva e a entrevista individual.

Em cada período, consultamos os alunos que desenvolveram seus "memoriais", a fim de saber seus respectivos interesses em continuar participando da pesquisa nas etapas subseqüentes. $\mathrm{Na}$ última fase, para a entrevista individual, os alunos foram escolhidos intencionalmente, de acordo com os critérios: a) alunos que se destacaram em relação às suas falas no interior dos grupos, muitas vezes levando os outros participantes a complementar ou a reproduzir suas idéias, b) alunos que, novamente, falaram sobre experiências diferenciadas com esportes e/ou atividades corporais dentro e/ou fora da escola; e c) alunos que demonstraram interesse em continuar participando da pesquisa.

Movimento, Porto Alegre, v. 14, n. 01, p. 85-110, janeiro/abril de 2008. 
Determinadas passagens dos "memoriais" expressaram percepções bastante subjetivas das trajetórias dos alunos, como as boas lembranças da infância na escolarização e na Educação Física; as lembranças negativas de uma vida sofrida, com pouco recurso financeiro e lembranças traumáticas de envolvimento com drogas e, em decorrência, de marginalização e exclusão por parte dos colegas da escola. Em alguns momentos, tive a impressão de que a memória dos alunos parecia materializar-se no registro escrito, tal como na história oral referida por Paul Thompson (1992). ${ }^{3}$ Às vezes, o que falavam parecia muito distante desse tempo, localizado em um passado muito longínquo, mas que se situava aproximadamente entre quinze e vinte anos.

Alguns chegaram a expressar saudades dos velhos tempos: "Lembro com saudades.... o recreio era quase sempre de 1 hora, jogávamos 'pelada', pique, subíamos nas árvores (tirar jaca, jambo, mexerica...), tempos bons" (Aluna do $9^{\circ}$ período). Outros perceberam que suas respectivas trajetórias influenciaram e/ou determinaram suas escolhas profissionais: "[...] agradeço a oportunidade de relembrar momentos, há muito, esquecidos em minha memória e, que sem dúvida, foram importantes para a escolha do curso que presto nesta universidade" (Aluno do $5^{\circ}$ período).

Um certo saudosismo marcou parte dos "memoriais"; por um lado, associado a experiências dentro da escola; por outro, a experiências fora dela. Em ambos, a experiência com esportes e/ou outras atividades corporais são características marcantes.

Pode-se dizer que as vivências escolares, nas aulas de Educação Física, no processo de escolarização no ensino fundamental e também no ensino médio, foram resgatadas pelos alunos a partir de caracterizações gerais, decorrentes das transformações da própria área ou de variações históricas, que podem ser consideradas elementos de análise em estudos no campo da sociologia do currículo - mais propriamente, na área da história das disciplinas escolares ${ }^{4}$.

\footnotetext{
${ }^{3}$ Ver mais a esse respeito em: THOMPSON, Paul. A voz do passado: história oral. Rio de Janeiro: Paz e Terra, 1992.

${ }^{4}$ Essa área busca explicar a gênese e a evolução das disciplinas escolares, bem como a predominância de_algumas tendências na organização e estruturação do conteúdo e nos métodos de ensino além de apontar as mudanças ocorridas ao longo dos tempos. Conferir em: SANTOS, Lucíola Licínio de Castro P. História das disciplinas escolares: perspectivas

Movimento, Porto Alegre, v. 14, n. 01, p. 85-110, janeiro/abril de 2008.
} 
Fora da escola, as vivências limitam-se, quase que exclusivamente, à prática esportiva em escolinhas de esportes, não deixando de ocorrer registros ligados à dança ou à ginástica.

A Educação Física como componente curricular na Educação Infantil, bem como as pesquisas sobre a Educação Física como prática social, nessa fase, são bastante recentes. Para Sayão (1997, p. 263), "[...] uma proliferação de "escolinhas infantis"”, nas décadas de 70 e 80, abriu perspectivas de um novo espaço de trabalho para profissionais de Educação Física. No entanto, algumas sérias críticas são levantadas sobre esse movimento apontando a precariedade da formação desses profissionais quanto ao trato com conhecimentos específicos para atuar na Educação Infantil, tanto na escola, como fora dela, além da crítica sobre a indefinição da identidade na área.

Os depoimentos não apresentam lembranças das aulas de Educação Física na Educação Infantil (0 a 6 anos). Entretanto, as trajetórias dos alunos, relacionadas com a vida escolar nas séries iniciais do Ensino Fundamental, indicam: a) influência da recreação: "A Educação Física era no pátio da escola. Lembro-me que participávamos de jogos e brincadeiras diversas, incluindo a tradicional queimada, acertar um alvo com uma bola [...]." (Aluno do $5^{\circ}$ período); b) influência do esporte - "A Educação Física acredito que não foi diferente da maioria das escolas públicas, onde quase sempre as aulas são de futebol para os meninos e vôlei ou queimada para as meninas [...]" (Aluno do $1^{\circ}$ período); c) ausência da Educação Física como componente curricular: "A Educação Física primária ( $1^{\mathrm{a}}$ à $4^{\mathrm{a}}$ série) não tinha nenhuma atividade, era apenas 'recreios' e às vezes, alguns ensaios para festividades." (Aluna do $5^{\circ}$ período); d) falta de um conteúdo estruturado e organizado por parte do professor da disciplina: "Cursei de $1^{\mathrm{a}}$ à $4^{\mathrm{a}}$ série em Escola Estadual do meu bairro (EEPG Antônio Esteves) [...]. Esta dispunha de uma quadra e bolas, mas a maioria das aulas de Educação Física consistiam em subir e descer o morro onde e escola se situava [...]" (Aluno do $9^{\circ}$ período).

de análise. Revista Teoria \& Educação, Belo Horizonte, n. 2, p. 27-32, 1990; CHERVEL, André. História das disciplinas escolares: reflexões sobre um campo de pesquisa. Revista Teoria \& Educação, Belo Horizonte, n. 2, p. 177-229, 1990; GOODSON, Ivor F. Currículo: teoria e debate. Petrópolis, RJ: Vozes, 1999.

Movimento, Porto Alegre, v. 14, n. 01, p. 85-110, janeiro/abril de 2008. 
Esses depoimentos evidenciam diferentes aspectos da Educação Física nas primeiras séries do ensino fundamental. Em Primeiro lugar, demonstram uma certa desorganização no trato com a disciplina como componente curricular, substituindo ou reduzindo os saberes da Educação Física para essa faixa etária a atividades com um fim em si mesmas. Em segundo lugar, no que se refere a influência do esporte, deixam explícito a questão de gênero presente desde as séries iniciais, também no interior da Educação Física.

Analisando algumas pesquisas ${ }^{5}$ a respeito da questão de gênero no ensino da Educação Física, observei elementos que se cruzam. Parece que as relações sociais entre o feminino e o masculino são construídas em separado, ao mesmo tempo em que o esporte ou a forma como é tratado, influencia e/ou determina para a consolidação dessa separação. Podemos identificar o cruzamento desses elementos quando o aluno enfatiza: "[...] futebol para os meninos e o vôlei ou a queimada para as meninas." Nesse caso, os respectivos conteúdos servem ou vem servindo para naturalizar as diferenças a partir do biológico e legitimar uma relação de dominação (ALTMANN, 1998).

As trajetórias relacionadas com a vida escolar nas séries finais do ensino fundamental indicam a predominância da prática esportiva como conteúdo principal: “[...] a Educação Física era muito dinâmica, com a realização de torneios internos em várias modalidades esportivas como também em nível municipal, quando tive a felicidade de participar de alguns (basquete, handebol, futebol) representando a escola" (Aluno do $5^{\circ}$ período).

A supremacia do esporte no ensino da Educação Física de $5^{\mathrm{a}}$ a $8^{\mathrm{a}}$ séries indica outra característica, às vezes, associada à questão de gênero já mencionada: a valorização dos mais aptos/habilidosos para a atividade esportiva: "Como eu já tinha uma boa conduta para o desporto, eu sempre era convocada para as equipes na qual eu compunha os times de futsal, voleibol, handebol e basquetebol. Assim, foram os quatro anos até eu concluir o fundamental: colecionando

\footnotetext{
${ }^{5}$ Dentre elas, a dissertação de mestrado: ALTMANN, Helena. Rompendo fronteiras de gênero: Marias (e) homens na educação física. 1998. Dissertação (Mestrado em Educação) - Programa de Pós-Graduação em Educação, Universidade Federal de Minas Gerais, Belo Horizonte, 1998.
}

Movimento, Porto Alegre, v. 14, n. 01, p. 85-110, janeiro/abril de 2008. 
medalhas" (Aluna do $5^{\circ}$ período), e em conseqüência disso, a exclusão $0^{6}$ dos considerados menos aptos/habilidosos para a atividade esportiva. Essa exclusão é lembrada por uma aluna do $5^{\circ}$ período no seguinte depoimento:

No ginásio ( $5^{\mathrm{a}}$ à $8^{\mathrm{a}}$ série) entraram algumas modalidades de jogos e atletismo e lembro perfeitamente de minha professora, muito bonita, elegante, simpática e carinhosa, mas acredito que para ela, alguns alunos sem porte atlético ou que não demonstrassem nenhuma habilidade específica para (queimada, vôlei, corrida com ou sem barreira, salto em altura ou extensão e etc...) atividades físicas, não eram estimulados ou não deveriam estar ficando à sombra daqueles que sobressaíssem. Eu era uma das sombras, era pequena (não desnutrida) e não tinha força alguma para um bom saque, uma boa impulsão ou uma boa velocidade, não era estimulada para me desenvolver e pouco fazia parte de campeonatos da escola. (ALUNA, $5^{\circ}$. Período)

Os sentimentos de frustração e incapacidade causados pela exclusão são marcantes. Em alguns casos, a exclusão, quase sempre, ligada ao estereótipo do porte atlético, levou à procura por outras atividades:

\begin{abstract}
Eu era uma criança gordinha que não gostava muito de Educação Física, pois era uma coisa obrigatória e que apesar de gostar e tentar praticar esportes, entrando no time da escola, não dava muito certo, pois nunca fui boa em esportes, mas eu gostava e praticava dança. (ALUNA, $1^{\circ}$ período).
\end{abstract}

São do sexo feminino os depoentes que apresentaram os três registros que sinalizam a exclusão que ocorre, fundamentalmente, por causa da forma como o esporte, enquanto conteúdo é tratado pelos professores nas aulas. Evidências de que a exclusão na Educação Física é uma ação discriminatória e está interligada com questões de gênero conforme evidenciado. Essa ação, algumas vezes, parece influenciar e/ou determinar a construção de experiências sociais

${ }^{6}$ Pode ser visto nos depoimentos que essa exclusão acontece tanto por parte do professor da disciplina quanto por parte do próprio aluno.

Movimento, Porto Alegre, v. 14, n. 01, p. 85-110, janeiro/abril de 2008. 
corporais "permitidas" e mais "apropriadas" às meninas, como a dança e/ou ginástica. Por terem passado pela experiência de exclusão, considerando os valores e sentimentos internos de frustração e de incapacidade, as três alunas construíram caminhos alternativos e, no curso, realizam escolhas coerentes com suas trajetórias.

O problema do "esporte na escola" tem sido discutido por vários autores da área. Tem sido problematizada, por exemplo, a transposição do esporte para dentro da escola sem maiores questionamentos sobre as normas e valores sociais com os quais ele vem impregnado, como a supervalorização da competição, a exclusão dos "menos habilidosos" e "mais fracos", a seletividade, o preconceito entre sexos, e outras contradições.

Há uma forte identificação com esportes por parte dos alunos e as instituições de ensino parecem aproveitar-se dessa predisposição, constituída socialmente, para consolidar/reproduzir o sistema esportivo, principalmente, no que se refere à seletividade para a formação de equipes escolares.

Com base nas diferentes definições sobre a ação mencionadas por Dubet (1994), essa ação individual de auto-exclusão dos alunos das aulas produz determinadas experiências sociocorporais na Educação Física e pode ser pensada como resultado de uma interação (modelo da comunicação) em que os alunos se relacionam com o professor, com outros alunos e com os saberes. Nessa interação, a ação de se auto excluir pode ser compreendida como uma maneira de manifestar a não identificação com aquele saber ou com a forma como ele está sendo desenvolvido e, também, como estratégia (modelo da ação racional) diante de alguma dificuldade ou de falta de interesse, não previamente decidida e que pode ser redefinida em meio ao desenvolvimento das aulas.

Por outro lado, não deixou de ocorrer, também, nos depoimentos, testemunhos de uma relação mais harmônica com a disciplina. Em menor proporção (nove, no total de vinte e oito) do que nos depoimentos anteriores de exclusão, frustração, sentimento de incapacidade, etc., essa relação harmônica é marcada pela forte identificação, dentro das aulas, de alguns alunos com o esporte.

Movimento, Porto Alegre, v. 14, n. 01, p. 85-110, janeiro/abril de 2008. 
No conjunto dos nove depoimentos, a relação mais harmônica ficou evidenciada por parte dos seis alunos do sexo masculino, e a relação de estranhamento, por três alunas do sexo feminino. $\mathrm{O}$ depoimento de uma das alunas declara:

\begin{abstract}
Quando cheguei na $5^{a}$ série, influenciada pela mídia, entrei para o time de voleibol do colégio, como era muito baixinha, fui ser levantadora. $\mathrm{Na} 8^{\mathrm{a}}$ série, ganhamos o estadual de escolas. Foram momentos muito divertidos que sempre me trazem boas lembranças $[\ldots]$ (ALUNA, $9^{\circ}$. período).
\end{abstract}

Outras duas alunas reafirmam o gosto pelas aulas de Educação Física por causa do conteúdo esporte:

\begin{abstract}
Na escola, sempre gostei muito das aulas de Educação Física e participei ainda das escolinhas de vôlei, handebol [...]" (Aluna do $1^{\circ}$ período). Sempre joguei de tudo mas a minha paixão foi e continua sendo o vôlei. $\mathrm{Na}^{\mathrm{a}}$ série entrei na seleção da escola ao mesmo tempo em que comecei a treinar pelo time do Atlético Tênis Clube de Vila Velha [...]. (ALUNA, $1^{\circ}$. período).
\end{abstract}

A identidade ou não dos alunos e alunas com o esporte, levandose em conta a forma como este vem sendo trabalhado nas aulas de Educação Física, parece gerar conflitos internos individuais e/ou coletivos. Se a(o) estudante gostar de determinadas práticas esportivas e conseguir se sobressair na turma, a ação pode ser de inclusão se a(o) estudante não gostar e não se destacar com relação aos outros alunos, a ação pode ser de exclusão. Em meio a essa prática comum, confirmada pelos relatos, as alunas são mais excluídas das aulas do que os alunos.

Se considerar os princípios dessa ação, conclui-se que há uma diversidade intrínseca que possibilita transformá-la em experiência; que essa ação não é previamente definida, mas que vai sendo estabelecida nas relações entre os alunos, o professor e a disciplina; que essa ação é fruto das relações vividas nas aulas. De maneira mais específica, que essa ação, resultante de lógicas de ação, é constitutiva das experiências sociais dos alunos, construídas na Educação Física antes do ingresso no curso.

Movimento, Porto Alegre, v. 14, n. 01, p. 85-110, janeiro/abril de 2008. 
A diversidade da qual falei remete à pluralidade e heterogeneidade de ações concretizadas pelos alunos dentro da disciplina em meio ao jogo de inclusão, exclusão e auto-exclusão das aulas, bem como à pluralidade de razões/lógicas pelas quais as ações acontecem. Sem dúvidas, essas ações vão sendo modificadas com as relações sociais vividas por seus respectivos atores.

Ao analisar esse jogo, específico e recorrente nos depoimentos, em que o esporte ou a maneira como vem sendo trabalhado é a grande responsável pela exclusão do(a) aluno(a), seja por parte do professor, seja pela própria iniciativa do aluno, percebemos que houve interseção entre as lógicas de integração, estratégia e subjetivação.

Observei duas lógicas de ação que se intercruzam. Apenas a título de melhor visualização, a integração ocorre, por exemplo, no caso em que os alunos, a fim de manter a integração coletiva, aceitam as "regras do jogo" escolar, ignoram os possíveis problemas e se integram, estrategicamente, nas relaçõses estabelecidas no processo da aula. A lógica de subjetivação parece se evidenciar de forma indireta, quando o(a) aluno(a) se experimenta como sujeito, se excluindo das aulas e escolhendo outras atividades que lhe proporcionem experiências sociais mais apropriadas às suas expectativas. Não é apenas a rejeição e auto-exclusão que entendo como subjetivação, mas a ação de substituir uma determinada experiência por outra que atenda melhor às expectativas e objetivos escolhidos. Pode-se dizer que, nessa ação, o(a) aluno(a) se experimenta como sujeito. Entretanto, a experiência sóciocorporal dos alunos em formação transita, comumente, pelas lógicas da integração e da estratégia.

\section{EDUCAÇÃO FíSICA NO ENSINO MÉDIO: ESPAÇO MAIS OU MENOS OCUPADO, EXPERIÊNCIAS SOCIOCORPORAIS MAIS OU MENOS CONSTRUÍDAS}

No ensino médio, as experiências não são muito diferentes. Se no ensino fundamental o problema maior é a forma como a Educação Física vem ocupando seu espaço no currículo escolar, no ensino

Movimento, Porto Alegre, v. 14, n. 01, p. 85-110, janeiro/abril de 2008. 
médio o problema maior é como a Educação Física não vem ocupando seu espaço no currículo escolar.

Um primeiro entrave é a própria ausência da Educação Física, apontada em sete dos vinte e oito "memoriais": "No segundo grau não tive a disciplina Educação Física por falta de professor, você deve saber, provavelmente, que a carência de professores no interior do Estado à esta disciplina curricular é grande [...]" (Aluno do $9^{\circ}$. período).

A falta de um trabalho planejado, estruturado e organizado, apontada em quatro registros, também parece ter incomodado bastante os alunos: "[...] a Educação Física não era levada a sério, não aprendi nada de bom, a professora só sabia fofocar e dar a bola para quem sabia e queria jogar [...]" (Aluna do $5^{\circ}$. período).

O fato de a preparação para o vestibular ter se tornado o principal objetivo do ensino médio, principalmente, em escolas particulares, que os alunos pesquisados freqüentaram, também representa um problema para a disciplina. Muitas vezes, o próprio aluno exclui a Educação Física e/ou atividades corporais, para usufruir de um tempo maior para estudos específicos: "Os jogos continuaram e eu até o $2^{\circ}$ ano, também não parei, no entanto, me privei dos treinamentos, e como já estava na equipe há muitos anos, os professores liberavam [...]. Assim, concluí o ensino médio, no entanto, eu virei uma legítima sedentária no $3^{\circ}$. ano" (aluna do $5^{\circ}$. período).

Essa auto-exclusão, como já disse, também acontece por ação estratégica pessoal na medida em que esta ação seja, por exemplo, de se ausentar das aulas, através de meios como atestado médico ou dispensa:

Infelizmente, ao final da $8^{\mathrm{a}}$ série, o professor de Educação Física que nos dava aula pediu demissão por motivos pessoais e seu substituto era, simplesmente, de formação questionável, pois todas as aulas ele somente perguntava 'o que vocês querem hoje' [...]. Sendo assim, decidi excluir-me das

Movimento, Porto Alegre, v. 14, n. 01, p. 85-110, janeiro/abril de 2008. 
aulas de Educação Física por meio de dispensas e assim, continuei até o segundo grau $[\ldots]^{7}$ (ALUNO do $1^{\circ}$ período).

Dois alunos que cursaram o ensino médio profissionalizante na antiga Escola Técnica Federal do Espírito Santo (ETEFES) relatam, situações vivenciadas na disciplina diferentes das vividas por seus colegas, acima citados. Trata-se de um trabalho esportivo sistematizado:

Neste período (1981 a 1983) a disciplina Educação Física teve um papel muito importante na minha vida. A escola dava ênfase muito grande a essa disciplina em diversos esportes (vôlei, natação, handebol, futebol, atletismo e basquete), com orientação precisa e adequada de professores capacitados e qualificados. Nesta época, participei da equipe de futsal da escola, o que me possibilitou integrar a equipe infanto-juvenil de futsal do Clube Álvares Cabral (ALUNO do $5^{\circ}$ período).

e de uma certa especialização esportiva por meio do treinamento:

Na ETFES consegui fazer parte da equipe de futsal no primeiro mês de aula ... Hoje, acho que foi pior para eu não ter participado das práticas esportivas que estavam à disposição, na época, pois desta forma, caminhei para a especialização (saber fazer uma única atividade, no caso dos esportes coletivos, o futebol) (ALUNO do $5^{\circ}$. período).

Mesmo com essa redução da Educação Física ao esporte constatam-se diferenças substanciais entre as práticas dessa disciplina em uma instituição de formação técnica e em escolas de formação geral, das quais os depoentes estudam.

Gariglio (1997), ao analisar o ensino da Educação Física em uma escola profissionalizante, indica sua posição privilegiada na hierarquia dos saberes escolares. Esse prestígio está ligado à organização da própria instituição, como a captação de recursos, a

\footnotetext{
${ }^{7}$ Esse aluno foi dispensado da Educação Física por ter sido atleta de Tae Kwon Do e, por conseguinte, participar da equipe de treinamento e competições de tal modalidade.

Movimento, Porto Alegre, v. 14, n. 01, p. 85-110, janeiro/abril de 2008.
} 
autonomia administrativa e pedagógica, a construção de estrutura física adequada, etc. Internamente, essa diferença de situações decorre do caráter eminentemente prático da disciplina e de sua associação ao trabalho corporal, bastante valorizado no ensino técnico, bem como de sua utilização no processo de socialização dos alunos, que também está relacionada à formação para o mundo do trabalho.

A trajetória desses dois alunos que freqüentaram o Ensino Médio profissionalizante indica experiências mais positivas com relação à Educação Física, em conseqüência de um trabalho mais bem planejado e de melhor qualidade.

\section{ONDE AS EXPERIÊNCIAS SÓCIOCORPORAIS CONSTRUÍDAS NO ENSINO FUNDAMENTAL E NO ENSINO MÉDIO PARECEM CRUZAR-SE}

No conjunto dos depoimentos/relatos é possível perceber alguns elementos recorrentes durante as experiências sociocorporais dos alunos, na disciplina, durante o ensino fundamental e médio. De um lado, a forte presença do esporte como conteúdo da disciplina, incluindo as implicações subjetivas decorrentes desse fato. De outro lado, o lugar da Educação Física na hierarquia dos saberes escolares, evidenciando o baixo prestígio da disciplina dentro do currículo, o que também define a forma como são construídas as experiências dos alunos neste campo. Esse fato é evidenciado pela ausência da disciplina em algumas escolas, a forma como era lecionada e até mesmo pela auto-exclusão dos alunos, sem maiores conseqüências para sua vida escolar. Além disso, o seu quase desaparecimento no final do ensino médio, para dar lugar às disciplinas acadêmicas que preparam para o vestibular, mostra o lugar secundário ou a falta de prestígio da disciplina.

As implicações subjetivas, às quais me referi, estão reveladas nos depoimentos dos alunos e alunas e demonstram aspectos que vêm contribuindo para reproduzir valores culturais intrínsecos ao esporte. Os depoimentos deixam implícito que os professores da

Movimento, Porto Alegre, v. 14, n. 01, p. 85-110, janeiro/abril de 2008. 
disciplina tomam o esporte como conteúdo principal e realizam sua transferência de fora para dentro das aulas sem considerar, contudo, que o planejamento, estruturação e organização do trabalho pedagógico deve ser diferenciado.

Tem sido muito discutido na literatura educacional o processo de constituição dos saberes escolares. ${ }^{8}$ Este último tem sido analisado como uma didatização de diferentes tipos de saberes com o propósito de torná-los escolarizáveis. Assim, é importante entender porque, no caso da Educação Física, talvez por ser um saber ligado a prática, ele é introduzido nas escolas sem sofrer este processo de didatização, de forma a torná-lo compatível com os objetivos e interesses da educação escolar. $\mathrm{O}$ fato de já estar sendo ensinado nas chamadas escolinhas de esporte, nos clubes, nos treinamentos esportivos, esse processo de didatização ocorre, sendo possível introduzi-la na escola sem muitas transformações. Desta forma, estes saberes não são, muitas vezes, recontextualizados de acordo com a lógica escolar, uma vez que ele já sofreu este processo. Essa transferência traz às aulas de Educação Física tais implicações subjetivas, como valorização dos mais habilidosos e fortes, exclusão, frustração, seletividade e realização de uma prática desprovida de um significado pedagógico. Paralelamente a essas implicações nas quais os alunos constroem suas experiências com a Educação Física, ocorrem, também, as implicações curriculares que contribuem para situar a disciplina em um plano inferior na hierarquia escolar.

Nesse sentido, o campo do currículo desenvolve questões relevantes. Conforme vimos, Michael Young $(1989 ; 1996)$, no trato com a Educação, prioriza a seleção e organização curriculares, além de estudar as relações de poder que consolidam as hierarquias.

Com base nesta consideração pode se explicar o lugar que a Educação Física ocupa no currículo, bem como das relações de poder a que ela está submetida. Além disso, é importante considerar a separação mente/corpo nas sociedades ocidentais.

\footnotetext{
${ }^{8}$ Vale à pena conferir o livro "Conhecimento Escolar: Ciência e Cotidiano", cuja autora discute o conhecimento escolar e suas inter-relações com o conhecimento científico e o conhecimento cotidiano. No último capítulo desse livro, aborda o conhecimento escolar (o processo de disciplinarização e o processo de mediação ou transposição didática)

Movimento, Porto Alegre, v. 14, n. 01, p. 85-110, janeiro/abril de 2008.
} 
Por ser uma disciplina eminentemente prática, a Educação Física passa a cumprir, sem que isso se torne explícito, uma função de legitimadora da divisão hierárquica entre trabalho manual e intelectual, ao mesmo tempo em que alguns professores da área tentam construir pressupostos que possam legitimá-la como prática social.

O desenvolvimento de atividades não escolares ou a procura por elas como indicações presentes nos "memoriais" são decorrentes de diferentes motivos: a) exclusão nas aulas em função do trato com o esporte; b) falta de um trabalho planejado, estruturado e organizado nas aulas de Educação Física; c) gosto pelo esporte; d) preocupação com a saúde; e) influência familiar; f) interesse estético; g) determinação médica.

Os primeiros três motivos são mais recorrentes e coincidem com a fase escolar em que o estudante encontra-se nas últimas séries do ensino fundamental ou do ensino médio. A definição do gosto por determinadas práticas corporais, aliada ao descontentamento com as aulas, faz com que ele (a) substitua a Educação Física por outra prática: "A academia (ginástica) também me ajudou a parar de praticar Educação Física na escola, me livrando dos esportes que eu gostava mas não sabia jogar" (Aluna do $1^{\circ}$ período). Esse depoimento demonstra que a aluna "opta" pela auto-exclusão das aulas e busca incluir-se em outra prática corporal.

Em outro "memorial", a opção parece ter proporcionado reflexões para além da simples substituição de atividades: “ [...] embora tivesse pouco estímulo físico, sabia que tinha um interesse por atividades corporais vindo a me matricular em uma escola de ballet e jazz, não necessariamente, atléticas e sim em seu caráter de bem estar, saúde, vida, prazer [...]”. (ALUNA do $5^{\circ}$. período).

Consideradas por vezes como prática competitiva e seletiva, por muitos estudiosos da área, as atividades não escolares descritas nos "memoriais" demonstram, em alguns casos, serem pouco competitivas e pouco seletivas. As aulas de Educação Física, entretanto, são, em grande parte, muito competitivas e muito

Movimento, Porto Alegre, v. 14, n. 01, p. 85-110, janeiro/abril de 2008. 
seletivas. Os relatos dos alunos que freqüentaram escolinhas esportivas ou de dança e ginástica, mesmo as que tinham como finalidade o treinamento/alto rendimento, trabalharam em uma perspectiva de desenvolvimento ou inclusão ${ }^{9}$ daqueles alunos no trabalho proposto. A Educação Física escolar fica, muitas vezes, à mercê da seleção natural.

De acordo com os depoimentos analisados, pode-se concluir que o modo como os professores, no ensino fundamental e no ensino médio, selecionam, planejam, organizam, transmitem e avaliam os saberes favorece a construção de um tipo de relação com a disciplina em que prevalecem concepções unilaterais da Educação Física como esporte, da Educação Física como saúde, favorecendo, ainda, a manutenção de crenças e mitos que influenciam diferentes visões, hierarquizações e trajetórias relacionadas às experiências sociocorporais. Pode-se, concluir, também, que esse modo de seleção, planejamento, organização, transmissão e avaliação dos saberes têm motivado alguns alunos a buscar, fora da escola, atividades que preencham o vazio deixado pela disciplina no âmbito da instituição escolar.

Outro aspecto que deve ser aqui mencionado é o fato de que a formação em Educação Física parece não conseguir mudar, em diversos casos, a internalização das experiências sociais ligadas à atividades corporais construídas pelos alunos no decorrer do ensino fundamental e médio e trazidas para dentro dos cursos de formação.

\section{As EXPERIÊNCIAS SOCIAIS DOS ALUNOS NA TRANSIÇÃO DO ENSINO MÉDIO PARA O ENSINO SUPERIOR: O MOMENTO DA ESCOLHA DO CURSO}

As situações que levam o aluno à escolha da Educação Física como profissão são bastante diferenciadas. Há situações em que a escolha representa uma primeira opção; outras em que representa

\footnotetext{
${ }^{9}$ Estou analisando apenas o conteúdo e a forma do trabalho realizado fora e dentro da escola. Entretanto, é preciso considerar as especificidades institucionais, pedagógicas e o aspecto financeiro. Este último, talvez force as escolinhas a realizar um trabalho menos seletivo já que depende do número de alunos para existir/funcionar.

Movimento, Porto Alegre, v. 14, n. 01, p. 85-110, janeiro/abril de 2008.
} 
uma segunda opção, depois de o aluno já ter cursado outra graduação; situações em que a escolha representa segunda, terceira ou quarta opção, após reprovações em vestibulares para outros cursos. Nessas situações, as experiências sociocorporais construídas anteriormente parecem ter influenciado nas respectivas escolhas.

A experiência com esportes e/ou outra atividade corporal, apesar de predominante, não foi referência exclusiva para os doze alunos que escolheram cursar Educação Física.

Parte dos alunos desse grupo já trabalhava na área há algum tempo e, por isso, de alguma maneira, se sentiram pressionados a obter uma formação superior. As experiências desses alunos que atuam na área sem uma formação acadêmica, é uma das experiências sociais, identificadas por nós, relacionadas com atividades corporais construídas antecipadamente à formação e incorporadas por esses alunos, principalmente, no que se refere à construção de uma concepção de Educação Física. Essas mesmas experiências são transportadas para o curso funcionando como "filtros" durante a formação.

Outra experiência identificada no grupo de alunos que escolheu a Educação Física como primeira opção, para além da experiência com esportes e/ou outras atividades corporais, foi a pretensão de mudar a imagem que as pessoas têm da Educação Física escolar:

Infelizmente, ao final da $8^{\mathrm{a}}$. série o professor[...] era, simplesmente, de formação questionável, pois todas as aulas ele somente perguntava 'o que vocês querem hoje' e a maioria da turma respondia que queria jogar futebol... Daí então veio a decisão de prestar vestibular para Educação Física, pois, além de ser graduado com faixa preta em Tae Kwon Do e dar aulas há mais de três anos, pretendo mudar a má fama de que Educação Física serve somente para 'jogar bola', dizendo a grosso modo [...]. (ALUNO, $1^{\circ}$. Período,"memorial").

Movimento, Porto Alegre, v. 14, n. 01, p. 85-110, janeiro/abril de 2008. 
Este depoimento mostra a presença de duas lógicas de ação de acordo com a Sociologia da Experiência. Nessa experiência, há um desenvolvimento que vai da lógica de ação estratégica para a subjetivação. A ação de o aluno ter se excluído das aulas por meio de dispensas pode ser compreendida como estratégia e a ação de escolher o curso, para tentar mudar a condição da Educação Física, pode ser compreendida como subjetivação, já que o aluno adotou uma postura diferente, de contraposição, e construiu seus próprios objetivos e expectativas para com a área, mesmo se considerarmos a visão limitada de que, para ele, em função da própria experiência de atleta, a Educação Física parece ser considerada como sinônimo de orientação de exercícios físicos.

Quatro alunos(as) do total dos vinte e oito realizaram outros cursos superiores antes de ingressarem na Educação Física. Nesse grupo, evidencia-se uma escolha mais segura, fruto de um amadurecimento pessoal e profissional. Os alunos representantes dessa situação buscam uma profissão mais prazerosa e, novamente, interligada ao gosto pela prática esportiva e/ou outra atividade corporal:

Apesar de ter feito um curso de graduação em uma
área que tinha muita afinidade com o meu emprego
atual, não era realmente aquilo que eu idealizava
como realização profissional. Sempre gostei mui-
to de praticar esporte e sempre enxergava a Edu-
cação Física como uma forma prazerosa de ganhar
meu sustento. (ALUNO, $5^{\circ}$. período/ "memorial").

Também houve influência familiar nas escolhas profissionais. O que o diferencia do grupo que escolheu a Educação Física depois do fracasso na tentativa de ingresso em outros cursos é que os alunos foram aprovados e terminaram os cursos que a família apoiou para, posteriormente, voltarem à universidade para cursar Educação Física.

No plano das lógicas de ação que constituem essa ação de "escolher" a Educação Física após reprovações em vestibulares para outros cursos, bem como a ação de escolher a Educação Física após a realização de outra formação superior, pode-se identificar a lógica da integração e a lógica da estratégia.

Movimento, Porto Alegre, v. 14, n. 01, p. 85-110, janeiro/abril de 2008. 
A primeira lógica manifesta-se na situação em que os alunos realizam tentativas de inserir-se em profissões comuns e tradicionalmente aceitas pela família. Pode-se dizer também que é uma ação na qual os alunos, a partir das relações familiares e sociais, tentam realizar expectativas de outrem. Olhando para esta ação à luz da perspectiva de análise de Pierre Bourdieu (1998), sobre a transmissão da herança, percebemos que há uma certa concordância desses alunos em aceitar/herdar ${ }^{10} \mathrm{a}$ influência/herança dos pais.

A lógica da estratégia predomina nas situações em que as condições socioeconômicas da família influenciam, levando a utilização da estratégia de realizar um curso mais aceito, para, posteriormente, cursar uma formação que atenda seus próprios objetivos, interesses e expectativas. Nessas ações, há que se considerar, sobretudo, a incidência dos fatores culturais levando à valorização de cursos legitimados socialmente.

No caso da escolha da Educação Física depois do fracasso na tentativa de ingresso em outros cursos é pertinente saber porque um grupo constituído por nove dos vinte e oito alunos fez outros vestibulares anteriores à aprovação em Educação Física.

Nesse grupo, identifica-se a afinidade com o esporte e/ou outras atividades corporais:

[...] no primeiro vestibular tentei Administração, por gostar de matemática. Não passei e resolvi, então, tentar Educação Física, que apesar de conter matérias que eu não gostava muito na época, era a área que eu gostaria de trabalhar, já que sempre gostei de práticas esportivas [...]. (ALUNA, $1^{\circ}$. período/"memorial").

Esses depoimentos indicam que a experiência ligada ao esporte ou mesmo à afinidade com atividades corporais é considerada, no momento da escolha, apenas se as influências sociais e culturais do aluno permitirem. De todas as influências possíveis, a família ainda parece ser a grande referência para que os alunos escolham carreiras

10 "Herdar é transmitir essas disposições imanentes, perpetuar esse conatus, aceitar tornarse instrumento dócil desse 'projeto' de reprodução..." (BOURDIEU, 1998, p. 232)

Movimento, Porto Alegre, v. 14, n. 01, p. 85-110, janeiro/abril de 2008. 
mais promissoras quanto ao retorno financeiro e social. Ao que nos parece, no caso do grupo de alunos que não foram aprovados em outros vestibulares, a formação em Educação Física não deve ser considerada como escolha propriamente dita, pois aconteceu, porque os alunos não passaram em vestibulares anteriores para outros cursos vistos pela família e por eles próprios como carreiras de maior prestígio. Vimos que o interesse desses alunos pela Educação Física existia e era forte, mas estrategicamente para satisfazer a família, ou a um desejo interior de prestígio social, os alunos inibiram este interesse. No entanto, por falhar em outros cursos, estes alunos terminaram fazendo Educação Física, mesmo mantendo a "ilusão" de que no futuro farão outros cursos. Todos estes alunos expressaram o gosto pela atividade física, talvez não possam assumi-la por vaidades, pressões sociais, busca de maior status social.

Um depoimento que aponta motivação diferente dessa identificação com o esporte me chamou a atenção. Uma aluna do $1^{\circ}$. período que escolheu o curso após tentativas de ingressar em outros cursos se destaca por ter sido a única dos vinte e oito alunos participantes da pesquisa a ter afirmado uma total falta de identidade com a área, porque, em sua trajetória, não se envolveu com esportes e/ou outras atividades corporais:

\begin{abstract}
No que tange a escolha da Educação Física, ela foi por acaso. Desde o $1^{\circ}$ ano do ensino médio, a literatura me induziu a escolha da Psicologia como curso [...] ("memorial"). Eu sou a pessoa assim, mais nada a ver para falar sobre os motivos da escolha porque eu nunca pratiquei nenhum esporte, o que eu fazia era na escola mesmo na aula de Educação Física... (ENTREVISTA EM GRUPO).
\end{abstract}

Nesse caso, a aluna parece ter utilizado a estratégia de escolher um curso cujo vestibular é menos concorrido, o que pode ser interpretado como principal objetivo do estudante é o de ter um diploma de curso superior. Bourdieu (1998) fala sobre isto de que sua escolha é determinada pelas chances de sucesso que você deslumbra. Se você sabe que não irá ser aprovada em um determinado curso, mas que poderá ser aprovado em outro, você

Movimento, Porto Alegre, v. 14, n. 01, p. 85-110, janeiro/abril de 2008. 
direciona seu interesse para este outro que lhe garanta mais possibilidade de sucesso. As pessoas tendem a tirar do horizonte aquilo que lhes parece inacessível, em uma forma de se livrar de possíveis frustrações.

A condição socioeconômica parece ter influenciado, pois alguns deles desistiram dos cursos ${ }^{11}$ escolhidos como primeira opção, por serem cursos muito concorridos, de difícil aprovação e, por isso, dependentes de boas condições financeiras da família para custear, se necessário fosse, consecutivos anos de curso pré-vestibular.

A influência dos pais no momento da escolha da profissão, sendo essa escolha a Educação Física, parece ser determinante e contraditória. Alguns incentivam a participação dos filhos em atividades corporais, às vezes, até de forma exacerbada, ${ }^{12}$ durante toda a infância e adolescência, entretanto criam resistências quando o filho faz sua opção pelo curso de Educação Física.

Na origem dessa contradição, existe o preconceito entre o trabalho com o corpo versus trabalho de natureza mais acadêmico e teórico. Além do desprestígio do magistério no meio social, há, ainda, como influência, a desvalorização financeira da profissão e as próprias experiências dos pais com a Educação Física nos tempos em que estudavam.

À luz da Sociologia da Experiência, a ação dos alunos do grupo de colocar suas experiências e/ou a identidade com a área em segundo plano, como uma "carta na manga", pode ser analisada na lógica de estratégia, a ser utilizada no momento certo. Percebemos, então, que, nessa ação de optar/escolher a Educação Física após reprovação em vestibulares para outros cursos, a experiência anterior do aluno com atividades corporais passa a sustentar uma estratégia, quando em um dado momento, após consecutivas reprovações em outros cursos, ele se permite ou lhe é permitido considerá-la. Em

\footnotetext{
${ }^{11}$ Os cursos mais relacionados foram respectivamente: Medicina, Psicologia, Odontologia, Administração e Direito.

${ }_{12}$ Profissionais da área se deparam à todo momento com uma torcida e cobrança descabíveis (existe este termo no dicionário?) dos pais em campeonatos esportivos escolares e não escolares ou mesmo com um pai desejando que o filho seja o jogador de futebol que ele não foi e uma mãe desejando que a filha seja a bailarina que ela não foi.
}

Movimento, Porto Alegre, v. 14, n. 01, p. 85-110, janeiro/abril de 2008. 
última instância, passa a ser uma opção apoiada pelos pais e bem vista por eles próprios, desde que não conseguiram ingressar nos cursos escolhidos anteriormente. Há uma diversidade que possibilita uma análise de que a experiência do aluno confunde-se com a ação estratégica quando o aluno a utiliza para escolher o curso. A experiência do ator, nestes casos, confunde-se com o recurso estratégico.

Existe, em todas as situações que levam a(o) aluna(o) à escolha da Educação Física, uma relação comum. Quer seja como primeira opção, quer seja como segunda, terceira ou quarta opção, a escolha esteve, de alguma maneira, em algum momento, relacionada às experiências com esporte e/ou outra atividade corporal de forma positiva ou negativa dentro ou fora da disciplina. Significa dizer, então, que as experiências construídas na Educação Física e fora dela são referências fundamentais para os alunos que ingressam no curso.

Identifiquei experiências múltiplas construídas pelos alunos participantes da pesquisa durante suas trajetórias e que influenciaram e/ou determinaram as respectivas escolhas. Pude perceber que a Educação Física favorece a construção de experiências negativas de exclusão e auto-exclusão, caso a(o) aluna(o) não se adeqüe à reprodução do sistema esportivo, principalmente, em termos de valores culturais intrínsecos ao esporte, mas também promove a construção de experiências positivas, no caso dos alunos que se integram ao sistema esportivo, por mostrarem aptidão e interesse por determinadas práticas. Notei, também, que a experiência corporal exterior à disciplina serve como substituição do trabalho pouco organizado e pouco estruturado que vem sendo realizado na disciplina no interior da educação básica.

É necessário reconhecer que essas e outras experiências, aliadas à desvalorização da Educação Física na seleção e organização curriculares, influenciam as ações, interações, escolhas e, sobretudo, servem de referência para que o aluno filtre o conhecimento acadêmico curricular mais condizente com sua trajetória e, por sua vez, com o que mais lhe interessa durante o processo de formação.

Movimento, Porto Alegre, v. 14, n. 01, p. 85-110, janeiro/abril de 2008. 
Fato é que essas experiências estão fortemente identificadas com uma concepção de Educação Física que é vista como campo do esporte, da atividade física ou da saúde, o que foi evidenciado em, praticamente, todos os depoimentos. A escolha da Educação Física representa, para esses alunos, a prática de atividades nas quais o aluno já teve uma experiência ou que ainda vai ter.

\section{FORMAÇÃO DOCENTE E EXPERIÊNCIAS SÓCIOCORPORAIS DOS ALUNOS: RELAÇÃO MECÂNICA?}

Não se deve cair no reducionismo de considerar que as experiências sociocorporais influenciam de forma direta, exclusiva e mecânica a formação inicial em Educação Física. Entretanto, é impossível deixar de lado as evidências colocadas até aqui, de que há uma estreita relação entre as experiências anteriores dos alunos e suas escolhas, de maneira que há mudanças substanciais no perfil de formação objetivado pelo currículo prescrito de formação profissional.

Alguns estudantes do curso de Educação Física não se vêem em processo de formação profissional. A representação que parecem fazer do curso está fortemente identificada com suas trajetórias individuais e com o prolongamento dessas trajetórias durante os anos de formação.

Fica, então, um convite aos leitores para retomar o artigo publicado por mim no ano de 2004 para entender melhor como as ações mobilizadas pelos alunos no decorrer da formação inicial indicam determinadas experiências construídas e associadas às experiências escolares nos ensinos fundamental e médio, bem como às experiências de transição para o ensino superior. Por um lado, experiências sociais favorecidas pelas trajetórias dos próprios estudantes; por outro, proporcionadas pelas hierarquias em torno da própria Educação Física. $\mathrm{O}$ artigo reflete, também, de que maneira os cursos de formação têm lidado com as experiências sociocorporais dos alunos em formação.

Movimento, Porto Alegre, v. 14, n. 01, p. 85-110, janeiro/abril de 2008. 
Social-corporal Experiences and Teacher Formation in Physical Education

Abstract: The objective of this article is to interpret/ to previously understand the social-corporal experiences of the constructed pupils the initial formation in Physical Education and the social-corporal experiences of the pupils in the transition of average education for superior education. The socialcorporal experiences of the pupils constructed in elapsing of the formation, the hierarquization of you discipline, the choices of you discipline and the relations with knowing them of these you discipline had been object of reflection in one another article already published in the Magazine Movement. I searched to interpret the flow of you say them social of the pupils of the course, from the writing of "memorials" of you say them of the interviews in individual group and.

Keywords: Physical Education teachers. Socioeconomics factors. Career choice.

\begin{abstract}
Experiencias Sociocorporais y Formação de enseñanza en la educación física

Resumen: El objetivo de este artículo está a interpret/ entiende las experiencias del social-cabo de las pupilas construidas la formación inicial en la educación física y las experiencias del social-cabo de las pupilas en la transición de la educación media para la educación superior. Las experiencias del social-cabo de las pupilas construidas en el transcurso de la formación, el hierarquización de ti la disciplina, las opciones de ti disciplinan y las relaciones con saberlas de éstos que disciplinas habían sido objeto de la reflexión en un otro artículo publicado ya en el movimiento del compartimiento. Busqué para interpretar el flujo de ti las digo sociales de las pupilas del curso, de la escritura de "monumentos" de ti decirlos de las entrevistas en grupo individual $y$.

Palabras-clave: Educación Física: enseñanza.

Factores socioeconómicos. Selección de profesión.
\end{abstract}

\title{
REFERÊNCIAS
}

ALTMANN, Helena. Rompendo fronteiras de gênero: Marias (e) homens na educação física. 1998. Dissertação (Mestrado em Educação) - Programa de

Movimento, Porto Alegre, v. 14, n. 01, p. 85-110, janeiro/abril de 2008. 
Pós-Graduação em Educação, Universidade Federal de Minas Gerais, Belo Horizonte, 1998

BOURDIEU, Pierre. As contradições da herança. In: NOGUEIRA, Maria Alice; CATANI, Afrânio. (Org.). Escritos de educação. Petrópolis,RJ: Vozes, 1998. p. 229-237.

CHERVEL, André. História das disciplinas escolares: reflexões sobre um campo de pesquisa. Revista Teoria \& Educação, v. 2, p. 177-229, 1990.

DUBET, François. Sociologia da experiência. Lisboa: Instituto Piaget, 1994.

FIGUEIREDO, Zenólia C. Campos. Formação docente em educação física: experiências sociais e relação com o saber. Revista Movimento, Porto Alegre, v. 10 , n. 1, p. $89-111,2004$.

FORQUIN, Jean Claude. Escola e cultura: as bases sociais e epistemológicas do conhecimento escolar. Porto Alegre: Artes Médicas, 1993.

GARIGLIO, José Ângelo. O ensino da educação física nas engrenagens de uma escola profissionalizante. In: CONGRESSO BRASILEIRO DE CIÊNCIAS DO ESPORTE, 10., 1997, Goiânia. Anais... Goiânia: CBCE, 1997. p. 177-189

GEERTZ, Clifford. A interpretação das culturas. Rio de Janeiro: Zahar Editora, 1978.

GoODSON, Ivor F. Currículo: teoria e debate. Petrópolis, RJ: Editora Vozes, 1999.

LOPES, Alice Ribeiro Casimiro. Conhecimento escolar: Ciência e Cotidiano Rio de Janeiro: Editora da UERJ, 1999.

SACRISTÁN, J. Gimeno. O currículo: uma reflexão sobre a prática. 3. ed. Porto Alegre: Artmed, 2000.

SAYÃO, Débora Thomé. A hora de... a educação física na pré-escola. In: CONGRESSO BRASILEIRO DE CIÊNCIAS DO ESPORTE. 10., 1997, Goiânia. Anais... Goiânia: CBCE, 1997. p. 261-268

THOMPSON, Paul. A voz do passado: história oral. Rio de Janeiro: Paz e Terra, 1992.

YOUNG, Michael. Currículo e democracia: lições de uma crítica à "nova sociologia da educação". Revista Educação e Realidade, cidade, v. 14, n. 1, p. 29-39, jan./jun.1989.

. A propósito de uma sociologia crítica de educação. Revista Brasileira de Estudos Pedagógicos, cidade, v. 67, n. 157, p. 532-537, set./dez. 1996.

Experiências sociais no processo de formação docente em educação física. Tese (doutorado em Educação) - Programa de Pós-Graduação em Educação, Universidade Federal de Minas Gerais, Belo Horizonte, 2004.

Movimento, Porto Alegre, v. 14, n. 01, p. 85-110, janeiro/abril de 2008. 
SANTOS, Lucíola Licínio de Castro P. História das disciplinas escolares: perspectivas de análise. Revista Teoria \& Educação, v. 2, p. 60-68, 1990.

Movimento, Porto Alegre, v. 14, n. 01, p. 85-110, janeiro/abril de 2008. 